\title{
Development of Concept Understanding and Problem Solving Ability of Chemistry Education Students Through Metacognitive Skills-Based Learning
}

\author{
Ijirana \\ Universitas Tadulako \\ Palu Sulawesi Tengah, Indonesia \\ ijiranarizal@yahoo.co.id
}

\begin{abstract}
This study aims to develop an understanding of chemical concepts and problem solving ability of Chemistry Education students through the application of metacognitive skills-based learning (MSBL) model. This study used research and development design, Activities were performed in this study. Firs, creating a learning device from MSBL model that has been declared valid, such as: class lectures, student activity sheets, and instruments test of understanding the concepts and problem solving ability. Second, implementing learning in the classroom using a device developed on the basic chemistry courses with a total sample of 65 student (two classes). Learning with teaching materials Stoichiometry and Chemical Equilibrium. Third, measuring the development of conceptual understanding and problem solving skills by giving a test to students before and after learning and analysing using the average value of the $\mathrm{N}$-gain. The measurement for problem solving in terms of the ability the four indicators, such as; understanding the problem, planning the problem solving, implementing plans, and evaluating the results. The results of the study show that: 1 ) from 20 concepts of the examination, there are 11 concepts have high category, 9 concepts are in fairly high category, and none of the concepts are in the low category. 2) Student understanding concept development from Stoichiometric learning to Chemical Equilibrium. About $4(31 \%)$ of stoichiometric concepts are in the average $N$-Gain less than 0.5 , but after learning Chemical Equilibrium, the average $N$-Gain is more than 0.5. 3) the ability of students in the first class is in as enough category due to the all of problem solving skill indicators, while in the second class of the Stoichiometry and Chemical Equilibrium studies, both of them have three and two problem solving skill indicators reach the high category. 4) The abilities of students in understanding the problem, planning, doing the problem solving and evaluating the result have developed before conducting the Chemical Equilibrium study rather than before conducting the Stoichiometry. 5) The ability of students to evaluate the result has been developed from the first class to the second class for about $13,3 \%$, although the development is still included as enough categorized. The results shows that students ability in understanding concept and solving problem increase from time to time after applying an instruction based on metacognitive skill.
\end{abstract}

Keywords—conceptual understanding, problem-solving ability, metacognitive skills

\section{INTRODUCTION}

Chemistry essentially aims to acquire the competence of science and technology as well as cultivate scientific thinking critically, creatively, and independently. Therefore, studying chemistry aims to learners have the ability to understand concepts, principles, laws, and chemical theories and apply them to solve problems in everyday life. Learners who have problem-solving skills and apply facts, laws, and learned principles are also possible to be able to think critically [1]. The ability to think critically also affects the ability to analyze information obtained in everyday life. According to [2] that problem-solving ability is one of the main quality parameters of a person in modern and scientific society because the person is always thinking scientifically so as to build new knowledge.

According to [3] the achievement of understanding and development of problem solving abilities in chemistry can be done using metacognitive skills. This statement is supported by several opinions, i.e : (1) The application of metacognition in learning can influence the acquisition, understanding, retention, and application of what has been learned and influences the efficiency of learning critical thinking and problem solving [4]. (2) Metacognition can regulate and improve the cognitive tactics and strategies that can be used in the problem-solving process so that learners' knowledge becomes broader, think more about their own teaching, and ultimately help learners to take on their own learning responsibilities [5 and 6]. (3) Metacognition influences the thinking process of learners how to apply what has been learned to solve problems [7].

According to [3] and [8] those skills are closely related to planning, monitoring, and evaluation skills that play an important role in organizing learners in the problem-solving process. Planning skills include making predictions, sorting strategies, and allocating time or selective attention before solving problems [9]. This planning skill refers to the initial activity of one's thinking about how, when, and why taking action to achieve the goal through a series of specific goals toward the main purpose of the problem [6]. Monitoring skills involve awareness of understanding and performance of a person's tasks [10]. This skill refers to a person's oversight activities against the cognitive strategies employed during the completion of the task in order to recognize the problem and modify the plan [6]. Evaluation skills are retrospective retrospective after event, when one looks back at a strategy that has been used and whether it leads to a desired outcome or not [6]. Therefore, by tapping into these metacognitive skills 
in learning can have an effect on improving understanding of the material learned and problem-solving abilities.

A Model of learning metacognitive skills has been designed by [12] and declared valid by the expert. The learning model is named Model of Metacognitive Skills Based Learning (MSBL model). This model has characteristics; First, supported by information-processing cognitive theories, meaningful learning theories, Vigotsky's constructivist social theory, the theory of metacognitive skills. Second, has a syntax with five phases, namely; Orientation, exploration, application of metacognitive skills, self-reflection, and followup planning. Third, the model has a conducive learning environment oriented in collaborative, cooperative, and metacognitive situations. Fourth, it has the goal of developing an understanding of concepts and problem-solving abilities.

Achieving the development of conceptual understanding and problem-solving abilities can be determined through the implementation of the MSBL model. Therefore, this describes the development of understanding of concepts and problem solving skills of 68 students in chemical education, especially for the students who have programmed Basic Chemistry courses.

\section{METHOD}

This study followed phase of research and development ( $\mathrm{R}$ \& D), design adapted from [13]. First, creating a learning materials in the basic Chemical Stoichiometry and Chemical Equilibrium, i.e: lesson plan and work sheet, instrument test understanding of concept as much as 40 items and problem solving skills 8 item. Both instruments are valid with an average of 0.65 and 0.75 [14]. Secondly, implementing the learning using MSBL models in chemistry education at Universitas Tadulako use the device that has been developed. The number of students enrolled in this study were 35 (first class). Third, measuring understanding of concepts and problem solving skills of students before and after the learning. Fourth, making improvements learning materials (lesson plan dan work sheet ) and use it again to 33 students.

The tests used to measure the understanding of chemical concepts developed based on basic competencies and indicators of achievement in the material concept of Stoichiometry and Chemical Equilibrium. The type of test used is a multiple-choice test with the reasons. Scoring every matter of understanding the concept of using a scale of 0-4 with details, i.e; score 4 , if the selection was right and the reason right; score 3 if the selection was wrong and the reason was right, score 2 if the selection was right and the reasons was wrong, score 1 if the selection was wrong and the reasons wrong, and score 0 (zero) with no answer.

Tests to measure the ability of problem solving was a test description with reference to the benchmark assessment. Scoring on an individual's ability to use scale-free, depending on the magnitude of the Weight of each item problem. Measurement of test scores of students ability to solve the problem in terms of the four indicators of ability, namely; understanding the problem, problem-solving plan, implementing the plan, and evaluating the of results [15]
Development of conceptual understanding and problem solving ability of students in the application of MSBL models were analyzed using the average value of the $N$-gain adopted from [16] along with its category. High category when the average $N$-gain is greater than or equal to 0.7 ; medium category if they are between 0.3 and $0.7(0.3 \leq \mathrm{g}<0.7)$ and low category when the average $N$-gain is less than 0.3 . Implementation of the learning MSBL model was performed on the material Stoichiometry and Chemical Equilibrium. This was due to a number of researchers [17], [18], [19] stated that Stoichiometry and Chemical Equilibrium are considered difficult by students and students can not solve the problem in that material.

\section{RESUlTS AND DisCUSSION}

\section{A. Development of Concept understanding Students}

Average gain is normalized on the topic of learning Stoichiometry shown in Fig. $1 N$-Gain Students' Understanding Concepts on Stoichiometry in the First Class (a), and in the Second Class (b).

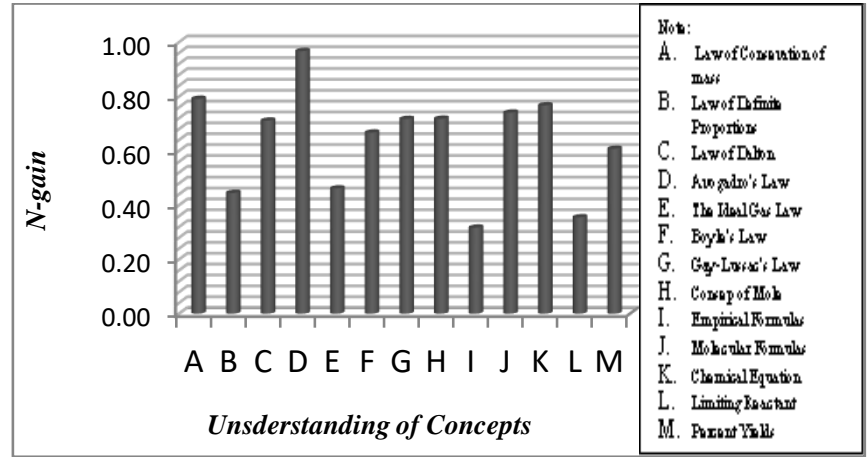

Fig. 1a $\mathrm{N}$-Gain Concepts Understanding Stoikiometry Student on First Class

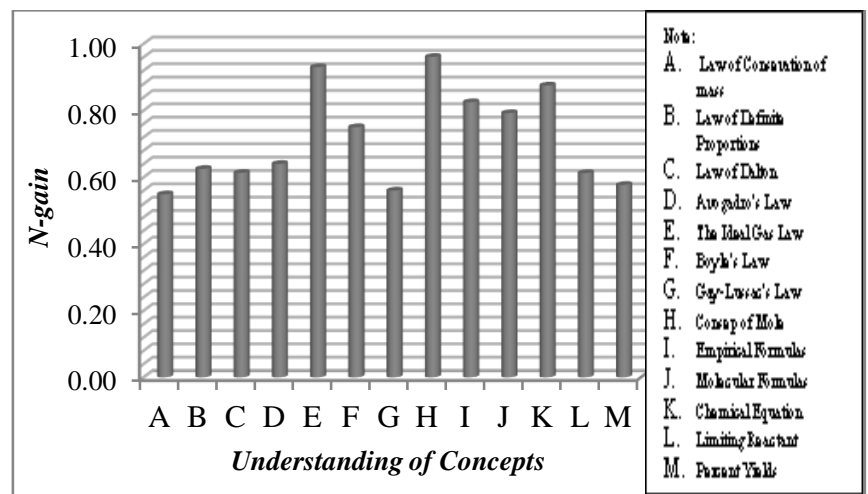

Fig. 1b N-Gain Concepts Understanding Stoikiometry Students in Second Class

The data in Figure show that; (1) general understanding of the concepts students on the material Stoikiometeri experiencing good growth after metacognitive-based learning is applied. More than $50 \%$ of the concepts taught understood by students with high category. Even in the second class, there are two concepts that have a high category with an average $\mathrm{N}$ Gain above 0.9, the ideal gas law and the concept of the mole. (2) understanding the concept of Stoichiometry students in 
second grade at the high category with an average of 0.72 . Higher than the average value in the first class that only 0.64 for all concepts tested. This fact indicates that the application of metacognitive skills-based learning model is able to develop the students' ability to understand, explain and apply the basic laws of chemistry, the concept of the mole, the molecular formula, chemical equation, the limiting reagent and concepts percent with good results.

The average gain is normalized to the learning topic Chemical Equilibrium given in Fig. $2 \mathrm{~N}$-Gain Students' Understanding Concepts on Chemical Equilibrium in the First Class (a), and in the Second Class (b).

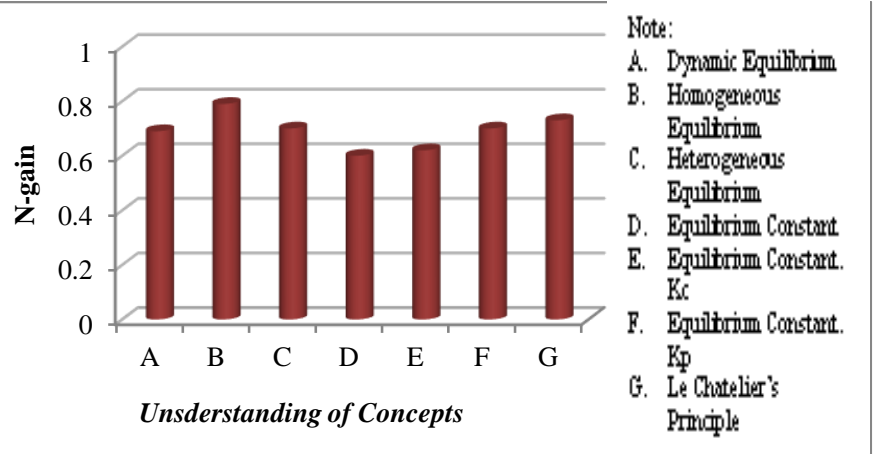

Fig. 2a N-Gain Concepts Understanding Chemical Equilibrium Student on First Class

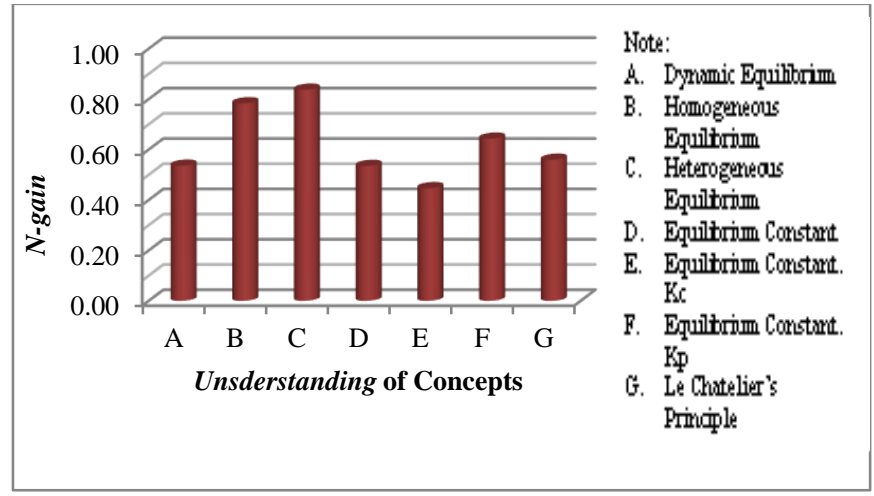

Fig. 2b N-Gain Concepts Understanding Chemical Equilibrium Student in Second Class

The data in Figure show that the general understanding concept of the student in Chemical Equilibrium has medium category with an average value of $N$-Gain 0.62 in the Second Grade and 0.69 in the First Class. This fact proves that there is a trend development of metacognitive skills of students from time to time so that the understanding concept students are also increase.

The test results of chemical education students conceptual understanding through the application of models MSBL on both topics indicate that; The first, from 20 concepts tested contained 11 concepts has high growth category conceptual understanding, 9 concepts has a fairly high category, and none of the concepts that are in the low category. Second, understanding concept students increased from Stoichiometry learning to Chemical Equilibrium learning. Learning outcomes Stoichiometry in the first class there are still has 4 concepts $(31 \%)$ of all concepts taught on the topic have $\mathrm{N}$ Gain is less than 0.5. However, none of the concept of Chemical Equilibrium with the average $N$-Gain is less than 0.5. This finding contrasts with the results [20] that the majority (>50\%) student teachers candidate have a lack of comprehension on the concepts of Stoichiometry and weak math skills from high school. Stoichiometric material characteristics that are abstract and require math skills lead students hard to understand the concepts of Stoichiometry well to be applied in solving problems. Therefore, through the application of models MSBL that emphasizes learning strategies metacognitive and provide opportunities for students to get the concept, discuss it with they colleagues and lecturer was able to increase the understanding of the concept of learners and develop ideas for science normative [21] although the material taught are abstract and require math skills. Thus, through the application of metacognitive skills-based learning model student understanding almost all the concepts of Stoichiometry and Chemical Equilibrium increased.

\section{B. Development of Problem Solving Ability Students}

Data from calculating the average gain is normalized on the topic of learning Stoichiometry and Chemical Equilibrium shown in Fig. $3 \mathrm{~N}$-Gain Problem Solving Ability Student in the First Class (a), and in the Second Class (b).

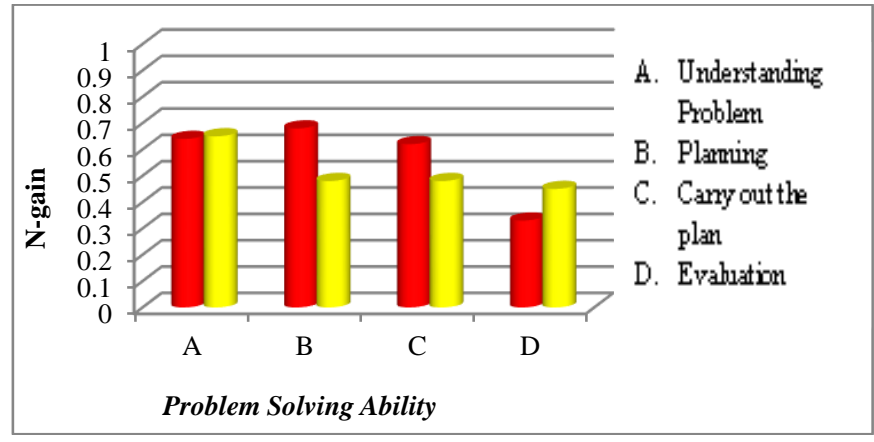

Fig.3a $N$-Gain Problem Solving Ability Student in First Class

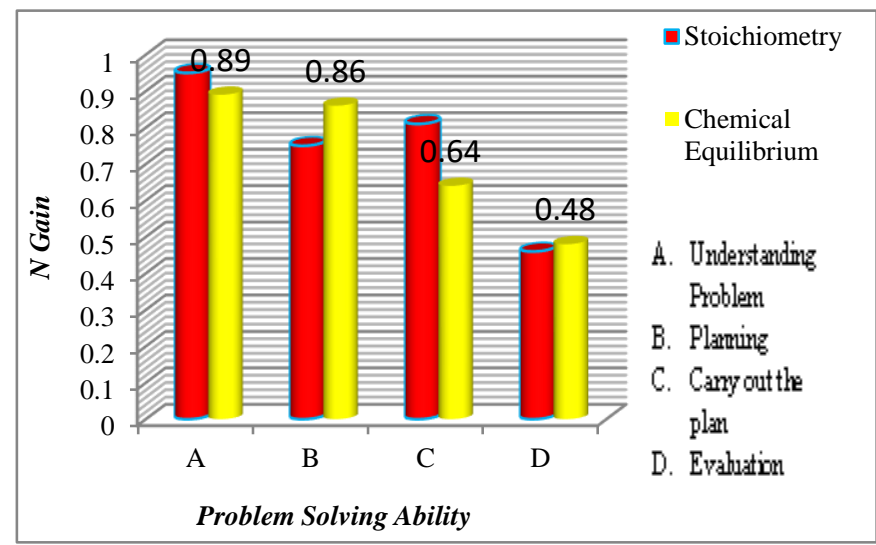

Fig. 3b N-Gain Problem Solving Ability Student in the Second Class

The data in Figures show that; the general ability of students to solve problems experienced significant development of the learning outcomes of the first class to 
second class after the application of metacognitive skills-based learning model.

The ability of students in the first class are still in the category enough for all indicators of problem-solving abilities, while the second class for learning the Stoichiometry and Chemical Equilibrium are respectively three and two indicators of problem-solving abilities have reached the high category.This success is due to the ability of students to translate statement of the problem, expressing they comprehension and factual knowledge, conceptual and procedural knowledge [22] were trained in metacognitive skill-based learning.

The ability to understand the problem, plan, implement plans, and evaluate the results in Figure $3 \mathrm{a}$ and $3 \mathrm{~b}$ show a fluctuating value on learning Stoichiometry and Chemical Equilibrium. This situation occurs because of an increase in the average of the four indicators before learning ability compared to Chemical Equilibrium before learning Stoichiometry. This means that the planning skills that make predictions, sort of strategy, and allocate time or attention before someone started to solve the problem will lead to better able to solve the problem [9] and [8]. Preventing from a trialand-error, and allows for the use of prior knowledge to determine what information is given and what is required [23]. The thinking activities indicate someone was using his cognitive variables in terms of translating skills and these skills are important predictors of problem solving skills [24].

The ability of students to evaluate the results also experiencing growth of learning in first grade to second grade of $13.3 \%$, although still in the category enough. This fact suggests that the overall indicators of problem-solving ability of students increased after some improvement MSBL learning implementation model. These capabilities have evolved over time and will continue to change for the better by familiarizing students use metacognitive skills. These results prove that students who were given attention in practice to solve the problem by applying metacognitive skills, discussion and self assessment can improve students' ability to identify problems, set goals, and develop good problem-solving strategies from time to time. This is in accordance opinions [25] that incorporate problem solving in collaborative learning, every student is involved with his colleagues arguing in the collaboration process and negotiate to improve knowledge. [26] also states that an important purpose in learning teacher metacognition is how students have an important role in learning, raise awareness, and to help take advantage of learning strategies to achieve goals. In addition, a person's ability to solve the problem depends on the individual's knowledge and expertise of a person. This means that not all the problems faced by a person is a problem for other people cause trouble someone solve a problem not because of the intrinsic characteristics of the problems encountered but rely on the knowledge and experience of problem solver [27]. Therefore, it appears that the ability of the students in this study is due to the many opportunities given to students to perform troubleshooting and judge him on his knowledge and problem solving so that students have a high confidence to be a good problem solver.

\section{CONCLUSION AND PROPOSITION}

Based on the results of the study concluded and suggested:

- Training metacognitive skills in teaching the application of Stoichiometry and Chemical Equilibrium is able to develop conceptual understanding and problem solving skills chemistry education students.

- The ability of students to understand the problem, plan, and carry out troubleshooting show a good development because the average ability of students at the high category. As with the students' ability to evaluate the results, this capability is progressing but is still in the category enough.

- Model MSBL to needed be shared through a further research on subjects such as physical chemistry and analytical chemistry.

\section{REFERENCES}

[1] R. Kirtikar, "A problem-solving approach for science learning," International conference new persfectives in science education. 2nd Edition, 2010.

[2] R., Mukhopadhyay, "Problem solving in science learning-some important considerations of a teacher," IOSR Journal of humanities and social science (IOSR-JHSS), vol. 6(8), pp. 21-25, 2013.

[3] M.M. Cooper and S. Sandi-Urena, "Design and Validation of Instrument To Assess Metacognitive Skillfulness in Chemistry Problem Solving,"Journal of Chemical Education, vol. 86(2), pp. 240-245. 2009.

[4] H.J. Hartman, "Developing Students' Metacognitive Knowledge and Skill," In Metacognition in Learning and Instruction Theory, Research, and Practice, Netherlands: Kluwer Academic Publishers. pp. 33-68, 2002.

[5] S.E. Israel, "Using Metacognitive Assessments to Create Individualized Reading Instruction". Newark, Delaware (DC): International reading association, 2007.

[6] A. Desoete, "Evaluating and Improving the Mathematics TeachingLearning Process Through Metacognition," Electronic Journal of Research in Educational Psychology, vol. 5(3), pp. 705-730. 2007.

[7] P. Rompayom, C. Tambunchong, S. Wongyounoi, and P. Dechsri, "The Development of Metacognitive Inventory to Measure Student' Metacognitive Knowledge Related to Chemical Bonding Conceptions," Paper presented at International Association for Educational Assessment (IAEA), 2010.

[8] G. Schraw, "Promoting General Metacognitive Awareness. In Hartman, H. J. (eds). Metacognition in Learning and Instruction. Theory, Research and Practice. pp. 3-15. Netherlands: Kluwer Academic Publishers, 2002.

[9] P. Metallidou, "Pre-service and In-service Teachers' Metacognitive Knowledge About Problem-Solving Strategies," Teaching and teacher education, vol. 25, pp.76-82, 2009.

[10] C. Balcikanli,"Metacognitive Awareness Inventory for Teachers (MAIT),"Electronic Journal of Research in Educational Psychology, vol. 9(3), pp. 1309-332, 2011.

[11] G. Schraw, and D. Moshman, "Metacognitive Theorie," Educational Psichology Review, vol.7(4), pp.351-371. 1995.

[12] Ijirana. "The design of instruction model based on the metacognitive skill for establishing problem solving ability and the understanding of chemical concept," International conference on mathematics, sciences, technology, education and their applications, Makassar Indonesia, pp. 281-291, August, 2014.

[13] W.R. Borg and \& M.D. Gall, Educational Research (An Introduction). Fourth Edition. New York \& London: Longman Inc., 2003. 
[14] Ijirana, "Practicality assessment device development of learning model based metacognitive skill," Internasional seminar on chemistry, pp. 1422, September, 2015.

[15] G. Polya, "How to solve it. second edition. princeton university press. 1973.

[16] R.R. Hake, "Interactive-engagement versus traditional methods: a sixthousand-student survey of mechanics test data for introductory physics courses," American. Journal Physics, vol. 66(1), pp. 64-74, 1998.

[17] P.E. Child and M.A. Sheehan, "What Chemistry Topics Do Students Find Difficult?," Proceedings of the 2nd European Variety in Chemistry Education. Prague. 2007.

[18] S. BouJaoude and H. Barakat, "Secondary School Students' Difficulties With Stoichiometry," School Science Review, vol. 81(296), pp. 91-98, 2000.

[19] M.S. Cracolice, J.C. Deming, and B. Ehlert, "Concept Learning versus Problem Solving: A Cognitive Difference," Journal of Chemical Education, vol. 85 (6), pp. 873-878, 2008.

[20] R. Hanson, "Ghanaian Teacher Trainess' Conceptual Understanding of Stoichiometry," Journal of Education and e-Learning Research, vol. 3(1), pp. 1-8, 2016.

[21] O. Eldar, B. Eylon, and M. Ronen, "A Metacognitive Teaching Strategy for Preservice Teachers: Collaborative Diagnosis of Conceptual Understanding in Science," In Metacognition in Science Education: Trends in Current Research, Contemporary Trends and Issues in Science Education, Springer Science+Business Media B.V, 2012.

[22] A. Weerawardhana, B. Ferry, and C. Brown, "Use Of Visualisation Software To Support Understanding Of Chemical Equilibrium: The Importance Of Appropriate Teaching Strategies," Proceedings of the 23rd Annual Ascilite Conference: Who's learning? Whose technology?, 2006.

[23] A. Desoete, and M.V.J. Veenman, "Metacognition in mathematics: Critical issues on nature, theory, assessment and treatment," In metacognition in mathematics education. New York: Nova Science Publishers, pp. 1-10, 2006.

[24] K.L. Lee, W. Tang, N. Goh, and L. Chia, The predicting role of cognitive variables in problem solving in mole concept," Journal of chemistry education: research and practice in europe, vol 2(3), pp. 285$301,2001$.

[25] R.C. Dixon, and K.C. Dixon, "Online Student centred Discussion: Creating a Collaborative Learning Enviroment," Proceeding ascillite melbourne, pp. 256-264. 2008.

[26] F. Takallou, "The Effect of Metacognitive Strategy Instruction on EFL Learners' Reading Comprehension Performance and Metacognitive Awareness," Journal Asean EFL, pp.272-300, 2010.

[27] T. Gok, "The general assesment of problem solving processes and metacognition in physics education," Eurasian Journal of Physics and Chemistry Education, vol. 2(2), pp. 110-122, 2010. 